December - 2009

\title{
The First Doctoral Program in Distance Education in North America
}

\author{
Dorothy (Willy) Fahlman \\ Athabasca University, Canada
}

\section{Athabasca University’s Doctoral Program in Distance Education}

The Doctor of Education (EdD) in Distance Education program at Athabasca University in Alberta, Canada was proposed in 2003. The program underwent a two-stage Alberta government review process and was approved in February 2007. This professional doctoral program is the first program of its kind in North America, combining advanced knowledge with research by connecting the university, the profession, and the workplace. The primary goal of the program is to provide doctoral students with rigorous and complete preparation to assume senior responsibilities for planning, teaching, directing, designing, implementing, evaluating, researching, and managing distance education programs (Athabasca University, Centre for Distance Education, 2008a). Based on a cohort model, the program begins with a five-day, faceto-face orientation workshop, followed by six online courses (18 course credits), a candidacy examination, and a dissertation defense. Courses include a variety of asynchronous and synchronous activities using technology-mediated conferencing.

The EdD (Distance Education) program at Athabasca University officially began in August 2008. Fifteen students were admitted into the first cohort of this program (13 students accepted admission). The following article will outline the historical development, program design, and innovative features of this new program. Further, the author will provide insights into students' initial reactions and early experiences during the first year of this program from the perspective of a student in the program.

\section{Athabasca University}

Athabasca University (AU) was established on June 25, 1970. AU was originally conceived as a traditional campus-based educational institution; however, in 1972, after a change in government, it changed direction to become an open, distance university. On April 12, 1978, AU achieved self-governing status and became fully accredited by the Government of Alberta as the province's fourth public university. In 2006, AU became the first Canadian public university to receive accreditation in the United States through the Middle States Commission on Higher Education (MSCHE) (Athabasca University, 2009). The university's philosophy is based on the key 
principles of excellence, openness, flexibility, and innovation (Athabasca University, 2009). It is committed to excellence in research, teaching, and scholarship.

Athabasca University currently offers over 700 courses in nearly 90 undergraduate and graduate degree, diploma, and certificate programs. The university focuses on providing flexibility of access and effective student support. Today, AU is one of the world's fastest growing online and distance education institutions, serving over 37,000 students worldwide. It has an annual operating budget of $\$ 118$ million, employs over 1,200 faculty and staff members on four Alberta campuses, and generates more than $\$ 3$ million annually in research activities (Athabasca University, 2009).

Prior to the commencement of the Doctor of Education in Distance Education program, AU offered eight graduate degree programs, all at the master's level:

1. Master of Arts - Integrated Studies,

2. Master of Business Administration,

3. Master of Business Administration in Project Management,

4. Master of Counselling (a part of the Campus Alberta Applied Psychology

Partnership),

5. Master of Distance Education,

6. Master of Health Studies,

7. Master of Nursing,

8. Master of Science - Information Systems. (Athabasca University, 2007, p. 13)

\section{Doctor of Education in Distance Education at AU}

The Doctor of Education (EdD) in Distance Education at Athabasca University is a professional doctoral degree (Athabasca University, Centre for Distance Education, 2008a). Professional degrees are currently available in disciplines such as education, health, law, psychology, management, the creative arts, and science (Neumann, 2005). The intended audience for this degree is practitioners and those with career experience in distance education.

The doctoral program, though relatively new in most professional fields, has a well-defined set of objectives and competencies:

1. understanding of and proficiency with professionally relevant knowledge and practice,

2. advanced research and communication skills, and

3. opportunity for advanced practice and socialization within a professional community. (Athabasca University, Centre for Distance Education, 2008a)

The professional doctoral degree fuses research and advanced knowledge by connecting the university, the profession, and the workplace (Neumann, 2005). To the professional workplace, the university brings experience and enables the linking of theory with practice, teaching, and research (Athabasca University, Centre for Distance Education, 2003). It is through the 
sponsorship of advanced professional study that the university increases its ability to provide resources, support, motivation, and credentialing for knowledge generation, research, and teaching in the field of study. In addition, the professional doctoral program also benefits from greater integration within the professional community (Athabasca University, Centre for Distance Education, 2003).

This transition to the professional workplace is aligned with Athabasca University's tradition of expansion of opportunity and openness for students (Athabasca University, Centre for Distance Education, 2003). It leads to skill development that is valued in the professional community and acts as a "visible indicator of Athabasca University's contribution to innovative forms of higher education and community service" (Athabasca University, Centre for Distance Education, 2003). Accordingly, the research component of the doctoral degree will lead to the discovery of new knowledge and the dissemination and implementation of such in the professional community (Athabasca University, Centre for Distance Education, 2003).

\section{Development, design, and features.}

In 2003, the Centre for Distance Education (CDE) at Athabasca University put forth a proposal for its first doctoral program in Distance Education. This program proposed to deliver the first online (non-residential) distance education doctorate in North America, offering a high-quality, alternative delivery program to graduates of AU's successful master's program in Distance Education (MDE) in addition to graduates of other master's programs (Alberta Advanced Education and Technology, 2008). The first convocation of MDE graduates was held in 1998. Since that time, MDE students, and others, have expressed a growing interest in pursuing a doctoral program in distance education (Advanced Education and Technology, 2008).

The objectives put forth for the doctoral program include the following:

1. to deliver a distance-accessible program which meets and exceeds current standards for doctoral programming for the advanced education of scholars and researchers in distance education;

2. to serve students seeking a doctorate in distance education who do not have access to an appropriate graduate program, or who prefer to pursue their graduate studies at a distance;

3. to provide a continuation to the current MDE program by providing doctoral studies to suitable graduates of the program; and

4. to meet the needs of a wide range of practitioners, scholars, and researchers in distance education, as the field evolves and expands. (Athabasca University, 2003, p. 13)

The target population for AU's doctoral program in Distance Education is individuals who have completed a graduate degree and who are involved currently in distance education. The online nature of the program facilitates access to students in non-urban areas, individuals with disabilities, students who are employed and who wish to study while continuing to work, and other potential students for whom the pursuit of a doctoral degree through a traditional 
educational institution would be difficult or impossible (Athabasca University, Centre for Distance Education, 2008e).

Potential students include the following:

- individuals in mid-career in distance education occupations, or in adult education and continuing education fields, as well as those responsible for policy development and implementation of distance, virtual, or alternative educational programs;

- those who wish to augment readiness for promotion or further growth in their careers, or to prepare for career change;

- individuals who are unable or unwilling to interrupt their careers to undertake a full-time, campus-based doctoral program, or who prefer the distance learning conditions of the online program;

- professionals with advanced degrees in various disciplines (e.g., university and college academics, teachers, instructors), who wish to specialize in aspects of distance education research and scholarship;

- $\quad$ senior-level staff in corporate, military, and industry training environments;

- instructional design specialists, senior-level managers and program planners, and others in areas related to the development of complex instructional systems. (This is an area where the proliferation of advanced educational technologies has resulted in the need for new learning systems design, development, management, evaluation, and research.);

- those employed in other areas related to the development of alternative or virtual learning systems, with mediated interaction among participants. (Athabasca University, Centre for Distance Education, 2008e)

Admission to the program is highly selective, with an intake target (exceeded in both of the first two intakes) of 12 students annually (Athabasca University, Centre for Distance Education, 2003). At year 4-5, the program will reach a steady state of approximately 40 students based on a projected student attrition of $33 \%$ over the course of the program. The program may be completed within seven years; however, most students are expected to complete it within four to five years (Athabasca University, Centre for Distance Education, 2003).

Core learning outcomes include the following:

1. development of analytic, evaluative, and procedural competencies in distance education as a field of study and practice, including historical and contemporary models and trends, and seminal research;

2. integration of the theoretical and practical application of available and prospective distance education delivery methods, their characteristics, economies and diseconomies, indications and contra-indications in practice, and their management, planning, and assessment requirements;

3. development of a theoretical framework regarding the use of technology-mediated instructional methods for the practical application of these methods in distance-delivered courses; 
4. development of analytic, evaluative, and procedural competencies in research design, practice, and dissemination, including oral presentation and writing skills;

5. application of various systems approaches to problem identification, analysis, and resolution, including management of complex operations and program development and coordination skills;

6. development of a theoretical framework and practical skills in the use of assessment strategies and evaluation methodologies in distance education;

7. application of teaching and learning principles within the context of a variety of distance education modalities, both as a learner and as an educator;

8. development of a theoretical framework regarding leadership models and change theories within the context of distance education organizations. (Athabasca University, Centre for Distance Education, 2007)

The doctoral program uses a cohort-based model. After students are admitted each year, they progress as a group through each phase of the program. This type of delivery format promotes collaborative learning and the development of a scholarly learning community. Secondarily, the cohort-based model may assist with program management and potentially may have administrative cost-savings benefits (Athabasca University, Centre for Distance Education, 2007). Initially, a five-day, face-to-face orientation workshop is conducted at AU for students and faculty to meet, to collaborate, and to be involved in program planning, community-building, and technological training activities. The program components consist of six online courses (18 course credits), a candidacy examination, and the completion of a dissertation and a dissertation defence.

The six program courses are described below:

1. Advanced Topics and Issues in Distance Education (3 credits) - current activity and thinking in the field of distance education; issues and topics, including relevant research;

2. Advanced Research in Education (3 credits) - distance education qualitative and quantitative research and evaluation studies; characteristics of good research and research methodology in distance education;

3. Teaching and Learning in Distance Education (3 credits) - advanced topics on teaching methods, research on teaching, and the development and delivery of distance courses;

4. Leadership and Project Management in Distance Education (3 credits) - leadership theories and practices and their application to the management and governance of distance education; management of change frameworks in distance education;

5. Research Seminar I (3 credits) - a supportive environment to engage in active discourse about dissertation research, including proposal writing, advanced research methods, and analyses;

6. Research Seminar II (3 credits) - active research and dissertation writing; opportunities to engage in scholarly discourse about dissertation research; exchange of ideas, discussion of experiences, and examination of the means for communicating the results of investigations. (Athabasca University, Centre for Distance Education, 2009b) 
The design for these courses includes a variety of delivery modes such as print, online, and faceto-face, comprising synchronous and asynchronous interaction, individual and collaborative learning, and various forms of technology-mediated conferencing (Athabasca University, Centre for Distance Education, 2003).

To meet the demands of this new program, 11 core CDE faculty members interact with students on study proposals, monitor student achievement, advise on dissertation-related work, consult with colleagues in dissertation committees within and outside AU, and maintain their own programs of research (Athabasca University, Centre for Distance Education, 2003). Involvement of the DE scholarly community is planned with colleagues from other distance institutions participating in the dissertation research and defense process. The AU Library's current holdings of core distance education books and journals are excellent, as are its service capabilities for doctoral students (Athabasca University, Centre for Distance Education, 2003).

A Program Advisory Board consists of internationally recognized distance educators, professional representatives, and potential employers of graduates (with suitable academic qualifications). This board provides advice on decisions about program content, delivery, and assessment to assure program quality and integrity (Athabasca University, Centre for Distance Education, 2003). Ongoing formative assessment is the responsibility of the CDE program director, in consultation with the Program Advisory Board (Athabasca University, Centre for Distance Education, 2003). External program review will occur after the second year and then at the $5^{\text {th }}$ and $10^{\text {th }}$ years. The program review will assess objectives relative to the program learning outcomes. This review includes a formal survey and analysis of outcomes in doctoral student work (Advanced Education and Technology, 2008).

The doctoral program has undergone a two-stage Alberta government review process that included a system coordination review of the proposed program to determine the need for the program and how it fits with other programs currently offered within Alberta's post-secondary system and an organizational and program quality review. The program was approved in February 2007 under Alberta's Post-Secondary Learning Act and the Approval of Programs of Study Regulation (Alberta Government, 2007).

\section{First Cohort of the Doctor of Education in Distance Education at AU}

In August 2008, the doctoral program in Distance Education at Athabasca University officially began. Admitted into this program were 15 students; however, one student declined and another student deferred commencement to the 2009 cohort. The gender distribution of the 13 remaining doctoral students consists of eight women and five men. According to Dr. P. Fahy, professor in the Centre for Distance Education at Athabasca University, the median age of the cohort is 53 years, while the mean age is 49 years (personal communication, January 8, 2009).

Dr. M. Ally, director of the Centre for Distance Education at Athabasca University, reports that this cohort of students has a variety of master's degrees including Distance Education (MDE), Education (MEd), Arts (MA), Science (MSc), and Arts - Integrated Studies (MAIS) (personal 
communication, September 20, 2008). All of the students are Canadian citizens, residing in five (out of 10) Canadian provinces from British Columbia to Newfoundland. The students are currently employed in the following areas:

1. four in health care education,

2. four as instructional/course/web designers,

3. three as instructors in colleges or universities, and

4. two in K-12 education

All of the students in this cohort are continuing their respective employment in addition to pursuing their doctoral studies in distance education with AU.

\section{Doctoral Students’ Initial Reactions and Early Experiences}

As a graduate of Athabasca University's MDE program, I met the final approval of the Doctor of Education in Distance Education program in February 2007 with enthusiasm and a sense that the long wait for a doctoral program that provided rigorous preparation for leadership and advanced responsibilities specifically in the field of distance education was over.

The application process for the first cohort of the program opened in November 2007. Selection was based "on the applicant's previous academic record, research track record, ability to participate in scholarly studies and conduct research independently at a distance” (Athabasca University, Centre for Distance Education, 2009a). During the application process, the CDE staff was very supportive and timely in responding to queries. Notification of acceptance into the program was sent to the successful applicants in February 2008.

In May 2008, course packages were mailed by postal service to students. Students appreciated not having to pre-order them. These packages included printed course readings and a textbook, so students were able to start their course readings before the commencement of the first course. Additionally, access to the open source Moodle learning management system (LMS) was provided, so students were able to login to the course website and post their introductions in the welcome forum. Following the dissemination of the course packages and access provisions for the Moodle LMS, the faculty member facilitating the first doctoral course contacted each student by telephone. This phone call was the students' preliminary introduction to faculty and provided an opportunity to discuss expectations and requirements for the first course and doctoral program. From the students' perspective, these initial endeavors were well received and illustrated the support and organization of the faculty and Athabasca University.

Although the program officially began in August 2008 with the face-to-face orientation week, a synchronous welcome session was held for students, using Elluminate ${ }^{\circledR}$ (Internet-based video/audio conferencing tool), at the beginning of June 2008. Students were introduced to faculty, provided with an overview of the upcoming orientation in August, and given an opportunity to pose questions. In addition, the initial assignment for the first doctoral course, EDDE801: Advanced Topics and Issues in Distance Education, was discussed. 
The first course assignment for EDDE801 required collaborative presentations at the mandatory August orientation "emphasizing both social and interpersonal growth among group members based on the work done together and the treatment of the assigned content" (Athabasca University, Centre for Distance Education, 2008b). Students were assigned to subgroups of three to four members and were required to select a topic for presentation based on the assigned course readings. During the three-month interval, from the welcome session in June 2008 until the inperson orientation week in August 2008, students collaboratively planned their respective presentations. This collaboration occurred at a distance, either asynchronously or synchronously, using e-mail, telephone, Elluminate ${ }^{\circledR}$, and Skype ${ }^{\circledR}$, an Internet-based video/audio conferencing tool. Initial trepidation was felt by most students due to their unfamiliarity with each other and their concerns related to previously committed activities during these months. However, as time passed, students became connected, developed greater rapport, and supported each other within the subgroups - such were the beginnings of our cohort learning model.

In August 2008, students, faculty, and administrative and support personnel met for the face-toface orientation week at the university in Athabasca, Alberta. Orientation is part of the first course, EDDE801: Advanced Topics and Issues in Distance Education. The stated objectives are as follows:

1. effectively access, throughout the remainder of their doctoral program, the resources of Athabasca University, in particular the Centre for Distance Education;

2. draw upon the interpersonal support, camaraderie, and intellectual stimulation of the cohort, based on rapport resulting from meeting and working together face-to-face with other students and faculty;

3. use various tools and procedures supported by Athabasca University for communications, assignment preparation and presentation, research, and data analysis;

4. adopt procedures for accessing, analyzing, notating, and storing for future reference important literature from the field of distance education and related areas;

5. discuss basic research findings, concepts, ideas, opinions, and trends as found in the core and supplemental readings, and apply these to issues in distance education practice;

6. practice collaborative development and presentation techniques and demonstrate these in the student presentation, at the program orientation, and in the EDDE 801 seminar sessions;

7. meet program faculty and begin the process of articulating and clarifying research interests and linking these with possible supervisors and committee members. (Athabasca University, Centre for Distance Education, 2008c)

The in-person orientation activities consisted of presentations by faculty and university representatives, including administrative, library, and technical staff. Students met with faculty advisers to consult and discuss research interests. Additionally, each of the assigned student subgroup presentations for the first assignment was completed. Synergies were created during 
the presentations and orientation as students were empowered, constructed meaning, developed collegiality, and gave and received support within the cohort. According to Saltiel and Russo (2001), learners' efforts increase in an education program that creates a learning environment for cohorts in which synergy is present. The students deemed this orientation as critical for setting the foundation to begin building a group relationship and a sense of community based on the "connection, belonging, and comfort that develops over time among members of a group who share purpose or commitment to a common goal” (Conrad, 2005, p.2).

Following this orientation, students participated in the EDDE801 course activities, both synchrously and asynchrously. Regular synchronous Elluminate seminars provided an opportunity for the delivery of course content, for additional collaborative learning activities, for interaction with guest speakers, and for didactic discourse on distance education. Asynchronous online forums using Moodle facilitated further interaction and critical reflection, providing the medium for each student to engage in dialogue and to moderate class discussion individually and collaboratively. In addition to the synchronous course seminars and asynchronous online discussions, synchronous sessions initiated by the cohort were held using Elluminate. These sessions provided a venue to discuss various topics as well as to enhance camaraderie and to offer collegial support. Faculty and students also conversed with one another using e-mail, telephone, and Skype. Interaction is a crucial element in distance education (Moore, 1991; Garrison \& Cleveland-Innes, 2005) as it reduces transactional distance and facilitates the construction of higher levels of knowledge and more meaningful understanding.

As discussed by Manos, McCoy, and Morgan (2005), a common stressor for graduate students in cohorts is time management. The carefully planned doctoral program structure provides clear participation requirements and context expectations. When the second course, EDDE802: Advanced Research in Education, began in the second term, concerns were voiced among students about the intensive scheduling of the course. As a group, students met synchronously on Elluminate and asynchronously by exchanging group emails to respond to each other's concerns, to collaborate as a cohort, and to come to a consensus on an action plan that would effect change. As a result of this cohesive focus, a group email was sent to the faculty articulating the students' shared perspectives and collective position on the EDDE802 schedule. "The cohort often becomes a powerful group in a brief period of time. Individual members combine together to act as one while the faculty and the administrators become the other force” (Saltiel \& Russo, 2001, p. 9). Faculty responded expeditiously, and via a combined student-faculty Elluminate session the intensive scheduling of the EDDE802 course was adjusted to assuage the cohort's time management concerns. While the doctoral students are evolving as change leaders, the faculty is embracing the power of the cohort.

Collaborative group work in EDDE802 also created challenges with time management due to outof-time and out-of-space virtual connectivity. Students were not only confronted with differences in time zones within Canada (from British Columbia to Newfoundland) but also internationally as several students were presenting at workshops/conferences in Nairobi, Spain, or Dubai. At the same time, the technology meant sometimes enduring balky connections. Through this group work, rich peer teaching occurred as students with distance instructional design experience 
encouraged novice online learners, thus facilitating communication and knowledge sharing. Time management issues with EDDE802 pushed the cohort to be creative and innovative, share knowledge, while accommodating individual differences, and problem solve collaboratively. "As with a finely tuned guitar when the change of one string produces a different sound, interwoven factors contributing to online learning community create a fluid and shifting dynamic" (Conrad, 2002, p. 18).

Another common stressor for graduate students, indicated by Manos, McCoy, and Morgan (2005), is financing their studies. A current limitation of this program is the lack of funding opportunities for students in their first year of studies. The total cost for the program is $\$ 41,840$ (Canadian) including textbooks (based on 2008 fee levels). Alternative funding sources are being sought by AU and by the doctoral students.

Throughout the first year of this doctoral program, individual stressors such as marital difficulties, family tragedies, illnesses, work commitments, and the birth of a baby influenced individual students' contributions and participation in the courses. However, during these times students collectively rallied around each other, promoting a sense of belonging and mutual support within the cohort. Other than the five-day orientation workshop at the beginning of the program, face-to-face networking opportunities among the doctoral students over the past year have been few. Some students have met at workshops/conferences or on an individual basis. However, although there was a high level of social presence in the online environment during the courses, students felt these limited face-to-face meetings were valuable. As Tisdell et al. (2004) state, group support may become a vital aspect of knowledge construction for students.

In addition to the cohort support, CDE administrative personnel and AU support staff have been exceptionally obliging in responding to queries and requests. Students are encouraged to communicate with their faculty advisers on a regular basis. The AU library has provided excellent service and support, sending out requested library resources in a timely manner.

\section{Conclusion}

Athabasca University has successfully launched the Doctor of Education in Distance Education program. Integral to this launch for the doctoral students has been the excellent pedagogical, developmental, institutional, and technological support at Athabasca University. As the president of AU, Dr. Frits Pannekoek, said, “Athabasca University has established itself as a world leader in providing high-quality distance education, and it is fitting that AU's first doctorate reflects our area of expertise ” (Athabasca University, 2008b).

As the second year commences, students in the first cohort of the EdD (Distance Education) program are developing strong social and cognitive presence as they collaborate, build relationships, challenge ideas, and construct knowledge through critical discourse. Accordingly, as the first cohort in the new program, we bring what we study to life. 


\section{Acknowledgement}

The author acknowledges the invaluable support of fellow AU doctoral classmates, Dr. Susan Moisey, Dr. Pat Fahy, and the CDE staff in the development of this paper. 


\section{References}

Alberta Advanced Education and Technology. (2008). Enrollment planning envelope, 18.

Alberta Government. (2007). Campus Alberta quality control council third annual report, 1 April 2006-31 March 2007. Retrieved from http://www.caqc.gov.ab.ca/pdfs/CAQC_2006-07_Annual_Report.pdf.

Athabasca University. (2007). Athabasca University annual report 2006 - 2007. Retrieved from http://www.athabascau.ca/report2007/.

Athabasca University. (2008a). News and events: Athabasca University to launch Canada's first online Doctorate in Business Administration (DBA). Retrieved from http://www2.athabascau.ca/aboutau/news/news_item.php?id=406.

Athabasca University. (2008b) History is made. au.world, 3(1). Retrieved from http://au.world.athabascau.ca/200809/lead.php.

Athabasca University. (2009). Athabasca University at a glance. Retrieved from http://www2.athabascau.ca/aboutau/glance.php.

Athabasca University, Centre for Distance Education. (2003). Step 1 proposal 2003, 113.

Athabasca University, Centre for Distance Education (2007, November). Learning outcomes. Retrieved from http://cde.athabascau.ca/programs/doctoral/outcomes.php.

Athabasca University, Centre for Distance Education. (2008a). What is an EdD? Retrieved from http://cde.athabascau.ca/programs/doctoral/edd.php.

Athabasca University, Centre for Distance Education. (2008b). EDDE801advanced topics and issues in distance education, assignment \#1-detailed description. $\quad$ Retrieved from http://cde.lms.athabascau.ca/mod/resource/view.php?id=5265.

Athabasca University, Centre for Distance Education. (2008c). EDDE801 - advanced topics and issues in distance education program orientation objectives. Retrieved from http://cde.lms.athabascau.ca/mod/book/view.php?id=5259.

Athabasca University, Centre for Distance Education. (2008d). Doctor of Education (EdD) in distance education. Retrieved from http://cde.athabascau.ca/programs/doctoral/index.php. 
Athabasca University, Centre for Distance Education. (2008e). Admission requirements \& procedures. Retrieved from http://cde.athabascau.ca/programs/doctoral/admission.php.

Athabasca University, Centre for Distance Education. (2009a). How to apply. Retrieved from http://cde.athabascau.ca/programs/doctoral/apply.php.

Athabasca University, Centre for Distance Education. (2009b). General information about the $E d D$. Retrieved from http://cde.athabascau.ca/programs/doctoral/intro.php.

Conrad, D. (2002). Deep in the hearts of learners: Insights into the nature of online community. The Journal of Distance Education, 17(1), 1-19.

Conrad, D. (2005, Spring). Building and maintaining community in cohort-based online learning. The Journal of Distance Education, 20(1), 1-20.

Garrison, D. R., \& Cleveland-Innes, M. (2005). Facilitating cognitive presence in online learning: Interaction is not enough. American Journal of Distance Education, 19(3), 133-148.

Manos, A., McCoy, R., \& Morgan, B. (2005). A case study of education Ph.D. cohort students: Factors related to stress. Journal of Continuing Higher Education, 53(2), 24-33.

Moore, M.G. (1991). Editorial: Distance education theory. American Journal of Distance Education, 5(3), 1-6.

Neumann, R. (2005, July). Doctoral differences: Professional doctorates and PhDs compared. Journal of Higher Education and Policy Management, 27(2), 173-188.

Saltiel, I. M., \& Russo, C. S. (2001). Cohort programming and learning. Malabar, Florida: Krieger Publishing.

Tisdell, E. J., Strohschen, G. I. E., Carver, M. L., Corrigan, P., Nash, J., Nelson, M., Royer, M., Strom-Mackey, R., \& O’Connor, M. (2004). Cohort learning online in graduate higher education: Constructing knowledge in cyber community. Educational Technology \& Society, 7(1), 115-127.

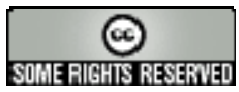

